\section{SOI: 1.1/TAS DOI: 10.15863/TAS International Scientific Journal Theoretical \& Applied Science}

\author{
p-ISSN: 2308-4944 (print) e-ISSN: 2409-0085 (online) \\ Year: 2017 Issue: 12 Volume: 56
}

Published: $30.12 .2017 \quad$ http://T-Science.org

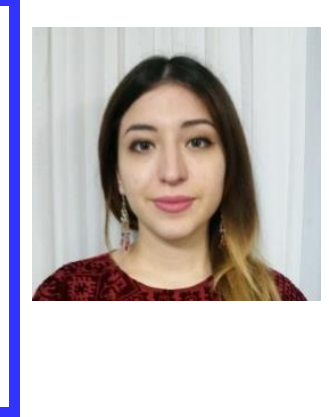

Fatima Avaz Bayramova junior researcher at the Institute of Economics of the National Academy of Sciences of Azerbaijan, doctoral student of the department

"Psychology" of Baku State University,

Baku, Azerbaijan Republic nauka-xxi@mail.ru

SECTION 21. Pedagogy. Psychology. Innovations in the field of education.

\title{
PSYCHOLOGICAL ASPECTS OF THE LEADER'S PERSONALITY IN THE PROCESS OF TAKING THE MANAGERIAL DECISIONS
}

\begin{abstract}
The article reviews the results of the study of the psychological characteristics of the leader's personality in the process of taking the managerial decisions. In particular, there was used Eysenck's proven methodology of identification of personality typology. It was revealed that the personality traits of the leader related to his temperament and character play a special role in the leadership style. In addition, professional qualities, age, gender, experience and qualitative composition of the team also play the defining role. It was revealed that the personal qualities of the manager in the organizations with a high level of integration (rigid management system) are not so important. Leaders with a predominance of phlegmatic temperament have a better chance of success.
\end{abstract}

Key words: management, psychology of management, leader's temperament and character.

Language: Russian

Citation: Bayramova FA (2017) PSYCHOLOGICAL ASPECTS OF THE LEADER'S PERSONALITY IN THE PROCESS OF TAKING THE MANAGERIAL DECISIONS. ISJ Theoretical \& Applied Science, 12 (56): 233-238.

Soi: http://s-o-i.org/1.1/TAS-12-56-38 Doi: crossef https://dx.doi.org/10.15863/TAS.2017.12.56.38

\section{ПСИХОЛОГИЯ ЛИЧНОСТИ РУКОВОДИТЕЛЯ ПРИ ПРИЕМЕ ИМ УПРАВЛЕНЧЕСКИХ РЕШЕНИЙ}

Аннотация: В статье рассматриваются итоги исследования психологических особенностей личности руководителя при приеме управленческих решений. В частности, использована апробированная методика Айзенка о типологии личности. Было выявлено, что особую роль в стиле руководства играют характерные черты личности руководителя, связанные с его темпераментом и характером. Кроме того, определяюшую роль играют профессиональные качества, возраст, пол, опыт и качественный состав коллектива. Было выявлено, что личностные качества руководителя в организачиях с высоким уровнем интегрированности (жесткая система управления) не имеют столь высокого значения. Руководителя с преобладанием флегматичности в темпераменте имеют больие иансов на успех.

Ключевые слова: управление, психология управления, стиль руководства, темперамент и характер руководителя.

\section{Постановка проблемы.}

В современных условиях проблемы психологии личности руководителя при приеме им важных управленческих решений часто становятся решающими для успешной работы предприятия или коллектива. Коммуникабельность, умение разложить существующие проблемы предприятия или коллектива требуют от руководителя, более взвешенного и порой единственного правильного управленческого решения по существу разрешения проблемы.

\begin{abstract}
Анализ последних исследований и публикаций.

В научных трудах А.Байрамова, А.Ализаде и Р.Алиева рассмотрены психологические аспекты и особенности личности руководителя при приеме им ключевых управленческих решений. Труды А.Китова, С.Рощина, Т.Разумова посвящены психологии руководителя хозяйственных субъектов. Э.Шпрангер, У.Джемс в своих работах рассмотрели типы и характеры индивидуальностей и психологии личности руководителя и т.д.
\end{abstract}




\section{Постановка задачи.}

Главная задача исследования является раскрыть сущность психологии личности руководителя при приеме им управленческих решений в нынешних непростых ситуациях и обосновать важность формирования психологической и мировоззренческого баланса личности руководителя для принятия оптимальных управленческих решений.

\section{Изложение основного материала} исследования. Сущность понятия личности в психологии. Одной из основных проблем современной психологии является проблема личности. Однако здесь нет единого подхода к психологии личности. Тем не менее, большинство исследователей считают, что на протяжении жизни личности формируются ее индивидуальные особенности, определенное мышление, поведение, возникают социальнопсихологические чувства В самом широком смысле человеческая личность есть интегральное единство и комбинация биогенетических, социои психогенетических элементов. Биологическая основа человека составлена из нервной системы, системыжелез, процесса обмена веществ (голод, жажда, половой импульс), половых различий,анатомических особенностей созревания и развития организма. Социальная природа человека определяется социальным устройством и культурой общества. Сущность личности определяется деятельностью различных социальных групп (семья, школа, сверстники и т.д.), его членством там, и его ролями, а также «Я» исравнение этого «Я» в рамках социогенетического содержания с другими людьми. Другими словами, здесь понимается комплекс личных представлений самого субъекта о себе на основе их представлений других людях.

В современной психологии нет однозначного подхода к проблеме личности. Однако большинство исследователей согласны с тем, что в понятие личности входят человеческие качества, которые формируются на протяжении всей жизни, определенное мировоззрение, образ поведения, чувственно-эмоциональный мир [2, c.220-221]. Согласно точке зрения знаменитого американского психолога Г.В.Оллпорта, личность - это динамическая организация психофизических систем, определяющих индивидуальное поведение и мышление. По мнению других исследователей (А.В.Петровский и М.Г.Ярошевский), в психологии личность есть совокупность качеств, которые человек приобретает в предметной деятельности и общении [1, с.51-52].

Вопросы теоретические направления проблемы личности в принятии управленческих решений отличаются актуальностью. По мнению большинства исследователей, процесс принятия решений является ключевым фактором для обеспечения эффективности процессов управления и занимает исключительное место в процессе управления. На самом деле, все функции процесса управления реализуются через принятие управленческих решений $[10$, с.32]. В понятие «принятие решения» вкладывается различное содержание в различных научных областях. В психологии понятие принятия решений включает в себя рядпсихических компонентов (мотивы, цели, правила, оценивание), которая имеют большое значение. А.И.Китов [4, с.174], вместо понятия «сумма индивидуальных характеристик руководителя, принимающего решения» предлагает понятие «личностный профиль руководителя». Согласно полученным данным, можно сказать, что насколько ситуация принятия решения сложнее и ответственнее, настолько эффективнее на это влияет личностный профиль человека. По словам Эриха Фромма, социальное развитие личности приводит к большей свободе и индивидуализации. Согласно его мнению, новая свобода связана с недоверием к собственным возможностям, неумением почувствовать собственные силы, сомнением, одиночеством и волнением. У него есть книга под названием «Бегство от свободы», где он назвал Америку больной страной. По его мнению, в конкурентном капиталистическом обществе формируются невротические личности, получающие функциональный невроз. Э.Фромм дифференцирует 4 типа личности: мазохист, садист, конформист и одиночка:

Человек мазохистского типа постоянно сталкивается в обществе с неудачами, в этих неудачах он видит только свою вину.

Человек садистского типа в своих неудачах винит только окружающее общество. Он воспринимает народ и миркак врагов и пытается уничтожить их. Всегда стремится к власти, господству, чтобы всех подавить и уничтожить.

Конформистский тип смешивается столпой, чтобы быть,как другие, быть похожим на них, не отличаться от них. Он всегда приспосабливается к условиям своего существования.

Одиночный тип всегда борется в одиночку, вдали от общества, чтобы быть вдалеке от ситуации, пытаясь убежать от нее [3, с.171-172].

Эдуард Спрейнджер на основе шести универсальных ценностных ориентаций выделяет шесть типов личности:

- теоретический: люди, выбравшие основным приоритетом эти ценности, всегда стремятся выявить истину;

- экономический: «экономический» тип личности, прежде всего,ценит то, что приносит пользу и эффект; 
- эстетический: этот тип человека отдает преимущество идеальной форме и гармонии;

- социальный: «социальный» человек предпочитает всему любовь и уважение к людям;

- политический: «властный» человек стремится к доминантной позиции политического типа. Этому типу людей присуща «человеческая сила»;

- религиозный: обычно склоннык идее о том, что мир управляется единым Богом, обладающим высокой управленческой силой [5,c.55-59].

У.Джеймс считал, что при формировании отношений понятие личности проявляет себя в трех отношениях:

структурные элементы;

чувства и эмоции (самооценка);

$[6$, c.59]

поведение (самозащита и забота о себе)

Следует отметить, что типология личности зависит от еe социальных ролей, стиля руководства (классификация К. Леви), одним словом, зависит от классификации различных профессиональных направлений.

П.Павлов выделял 4 типа высшей нервной деятельности, причем дифференцировалтри «чисто человеческих типа»: мыслительный, художественный, средний.

В основе типологии Павлова лежит участие первой и второй сигнальных систем в познании мира, в том числе в организация человеческой деятельности.

C точки зрения Павлова, представители мыслительного типа активности второй сигнальной системы в левом полушарии мозга, склонны к абстрактно-логическому мышлению, стремлению полностью понять логику принятия решений, детально анализировать события жизни. Такой тип людей любит математику, философию, их привлекает деятельность в научной сфере.

Представители художественного типа активности второй сигнальной системы в правом полушарии мозга обладают развитым образным мышлением. Люди со склонностью изучать искусство, культуру, поэзию, музыку, театр, отличаются при этом высокой эмоциональностью.

Большинство людей (до 80\%) принадлежат к «золотой середине», их эмоциональное или рациональное начало зависит от воспитания или жизненной ситуации. Типологические качества начинают проявляться с 10-16 лет. Подростки в этот период склонны заниматься литературой, искусством, другие же - шахматами, физикой, математикой, и т.д.

В процессе принятия решения основными функциями по принятию решений являются следующие: руководство в принятии решений;постановка проблемы, выбор критериев по ее конкретизации и оценке; реализация принятия решения в жизнь; организация исполнения решения и контроля над ним. В процессе принятиярешения решающую роль играет личностно-психологическая характеристика того, кто принимает решение: воля, умение внушать, эмоциональный уровень, характер, внимание, точность, склонность к риску, параметры мышления (глубина, широта, скорость и подвижность мышления). Основные качества руководителя (субъекта), принимающего решения можно разместить, на наш взгляд, в следующем порядке:умение точно формировать цель как ожидаемое следствие деятельности; умение всесторонне анализировать проблемную ситуацию; высокий уровень интеллекта, способность принимать решения в нестандартных ситуациях; развитая интуиция: умение принимать решение без наличия логического основания; творческий подход к способности управлять; способность идти на обоснованный риск и прочее. Перечисленное является основными компонентами подготовки к принятию решений и выступает основным ядром общепсихологической подготовки руководителя к руководящей деятельности. Практически каждое управленческое решение воплощает в себе индивидуальность и систему ценностей того, кто его принимает [9, с.48]. В подобном понимании человеческий фактор проявляется двояко: влияние на подготовку решения личностной характеристики и личностная оценка уже принятого решения. К личностной характеристике, как правило, относят следующее: волю, внушаемость, эмоциональность, темперамент, профессиональность, опытность, ответственность, ответственность, здоровье, параметры мышления (глубина, широта, скорость, подвижность). Глубина познания включает в себя его аналитический характер, возможность поиска при анализе ситуации причинно-следственных отношений. Широта это выражение синтетического характера мышления. Когда субъект, принимающий решение, может оценивать по сценарию общего действия роль и значение анализа.

С точки зрения воздействия на процессы характеристику личности можно классифицировать следующим образом: 1.Фиксированные постоянные: темперамент, реакция в генетическом аспекте, типа высшей нервной деятельности; 2.Слабые переменные: внушаемость, эмоциональный уровень, характер, организованность, склонность к риску, параметры мышления; 3.Сильные (быстрые) переменные: воля, ответственность, коммуникабельность (общительность). Согласно В.Смирнову [9, с.46], в процессе подготовки 
управленческих решений решающую роль играют личностные качества субъекта (руководителя), принимающего решение: практичность, оптимизм и пессимизм. В то же время следует учесть, что личностные психологические качества проявляют различную степень устойчивости. С этой точки зрения оценка относительно устойчивости проводится с трех позиций: 1) неизменные качества: темперамент, характерная генетическая реакция, тип высшей нервной системы; 2) слабые переменные: внушаемость, эмоциональный уровень, характер внимания, склонность к риску, параметры сознания; 3) сильные переменные: воля, ответственность, коммуникативность. В процессе принятия решения, по мнению В.Смирнова, выявляется различное содержание стилей поведения в зависимости от типа темперамента: 1) холерик: отдает предпочтение скорости, оперативности и индивидуальности в принятии решений. Однако они не всегда добиваются точного анализа ситуации и формирования реальной проблемы. Решения порой носят спонтанный характер. Принятое решение характеризуется высоким риском, решимостью и непреклонностью; 2) сангвиник: обладает более спокойной умственной деятельностью. Также, как и холерики, в процессе принятия решений показывают оперативную и быструю деятельность. Однако предпочитается рассматривать основные проблемы, или же основные элементы принятых решений на основе коллективного рассмотрения, a не единоличного решения; 3) флегматик: в отличие от применения уже принятых решений предпочитают сам процесс индивидуальной подготовки решений. Для них решающими оказываются мнения и советы, а также избыточная информация. Их решения отличаются высоким уровнем продуманности и безопасности. В реализации решений они решительны и упрямы.Вместо информационных систем предпочитают мнение специалистов; 4) меланхолик: Очень ответственный подход к процессу принятия решений. Стремятся учесть все негативное, что может быть результатом реализации решения. Во многих случаях на передний край выводятся незначительные проблемы или различные детали. Меланхоликам требуется много затрат, большие объемы информации, требуются многочисленные консультанты. Их решения отличаются детальной разработкой и реальностью реализации. Это не те, кто может работать в стрессовых ситуациях. Они хотят постоянно контролировать процесс реализации решений, помогают исполнителями стремятся проникнуть вглубь проблемы[8].

Отметим, что проведо экспериментальнопсихологическое исследование среди 23 начальников отделов Института экономики Национальной Академии Наук Азербайджана (8 женщин, 15 мужчин) и в Агентстве обязательного медицинского страхования среди 12 начальников отделов (6 женщин, 6 мужчин), на основании оценки годичной деятельности руководимых ими отделов. Приводим данные проведенного исследования на основании личностного опросника Айзенка [7, с.155].

Таблица 1

Корреляция показателей типов личности и темперамента опрошенных руководителей на основании личностного опросника Айзенка, а также годичных отчетов отделов, которыми они руководят

\begin{tabular}{|c|c|c|c|c|c|c|c|c|}
\hline \multirow{3}{*}{ Типы личности } & \multirow{3}{*}{$\begin{array}{c}\text { всего } \\
\text { человек }\end{array}$} & \multirow{3}{*}{ в \% } & \multicolumn{6}{|c|}{ Деятельность отделов на основании годового отчета } \\
\hline & & & \multicolumn{2}{|c|}{ низкий } & \multicolumn{2}{|c|}{ средний } & \multicolumn{2}{|c|}{ высокий } \\
\hline & & & всего & в \% & всего & в \% & всего & в \% \\
\hline Интроверсия & 19 & 54,2 & 4 & 11,4 & 6 & 17,1 & 9 & 25,7 \\
\hline экстраверсия & 16 & 45,7 & 1 & 2,8 & 7 & 20 & 8 & 22,8 \\
\hline \multicolumn{9}{|c|}{ Типы темперамента } \\
\hline сангвиник & 4 & 11,4 & 0 & 0 & 1 & 2,8 & 3 & 8,5 \\
\hline флегматик & 17 & 48,5 & 4 & 11,4 & 5 & 14,2 & 8 & 22,8 \\
\hline холерик & 8 & 22,8 & 1 & 2,8 & 5 & 14,2 & 2 & 5,7 \\
\hline меланхолик & 1 & 2,8 & 0 & 0 & 0 & 0 & 1 & 2,8 \\
\hline $\begin{array}{l}\text { Сангвиник- } \\
\text { флегматик }\end{array}$ & 2 & 5,7 & 0 & 0 & 1 & 2,8 & 1 & 2,8 \\
\hline $\begin{array}{l}\text { Холерик- } \\
\text { меланхолик }\end{array}$ & 3 & 8,5 & 0 & 0 & 1 & 2,8 & 2 & 5,7 \\
\hline
\end{tabular}


Как видно из таблицы 1, соответственно типологии личности, $54,2 \%$ руководителей интроверты, 45,7\% же - экстраверты. Согласно полученным данным, в целом сложно определить, какой тип личности обладает более эффективным стилем управления. Согласно годичным отчетам, деятельность 25,7\% интровертов и $22,8 \%$ экстравертов руководителей отделов была оценена достаточно высоко. Средние показатели были у 11,4\% интровертов и $2,8 \%$ экстравертов. Низкие показатели были у $17,1 \%$ интровертов, $20 \%$ экстравертов.

Можно сделать вывод о том, что каждый из указанных типов личности выдает положительные результаты при принятии управленческих решений. Вместе с тем следует учитывать и такой фактор, как низкий уровень представленности экстравертов среди руководителей с низкими показателями в работе. В Таблице 1 также показана взаимосвязь между типами темперамента руководителей отделов и характером представленных годичных отчетов. Среди руководителей выявлены следующие типы (в процентах): $11,4 \%$ - сангвиники, 48,5\% - флегматики, $22,8 \%$ - холерики, 2,8\% меланхолики, 5,7\% - сангвиники-флегматики, 8,5\% - холерики-меланхолики.

Между типом темперамента руководителей отделов и управленческой деятельностью выявлена следующая связь: $8,5 \%$ руководителей с темпераментом сангвиника показали высокий уровень руководства, а 2,8\% - средний уровень. Низкий уровень руководства был выявлен у лиц с темпераментом сангвиника. 22,8\% представителей типа темперамента флегматика показали высокий, $2 \%$ - средний, 11,4\% - низкий уровень руководства; 5,7\% представителей темперамента холерика показали высокий, 14,2 \% - средний, 2,8\% - низкий уровень деятельности. Меланхолический тип темперамента был зафиксирован лишь у одного руководителя $(2,8 \%)$, однако годичная деятельность отдела получила высокую оценку.

Смешанный тип темперамента, сангвиникмеланхолик, показал себя выше на 2,8\%, холерик-меланхолик - на 5,7\% выше,и на 2,8\% - у руководителей среднего уровня.

Таблица 2

\section{Показатель нейротизма на основании методики личностного опросника Айзенка}

\begin{tabular}{|ccc|}
\hline нейротизм & всего & $6 \%$ \\
стабильный & 24 человека & $68,5 \%$ \\
нестабильный & 11 человек & $31,4 \%$ \\
\hline
\end{tabular}

Во второй таблице была измерена шкала нейротизма, показывающая состояние волнения, тревожности, эмоциональную изменчивость, депрессивность. На основании полученных результатов можно сделать выводы о том, что
68,5\% начальников отделов обладают стабильным, а $31,4 \%$ - нестабильным нейротизмом. Большинство руководителей показало стабильные результаты.

\section{Шкала искренности в соответствии с методикой Айзенка «Личностный опрос»}

\begin{tabular}{|ccc|}
\hline Шкала искренности & число опроменных & в \% \\
искренние & 27 & 77,1 \\
искренние (в зависимости от обстоятельств) & 6 & 17,1 \\
неискренние & 2 & 5,7 \\
\hline
\end{tabular}

В целом, как видно из шкалы, 77,1\% руководителей ответили на вопросы искренне, $17,1 \%$ искренне в зависимости от условий, 5,7\% неискренне. Все это дает нам основание считать, что респонденты озвучили вопросы теста вполне адекватно.

\section{Выводы из проведенного исследования.}

Из теоретического и практического хода исследования становится ясным, что личность руководителя оказывает определяющее влияние на принятие им управленческих решений. Было определено, что тип личности руководителя не играет столь существенной роли в успешном руководстве отделом. С небольшим разрывом в показателях экстраверты $(22,8 \%)$ и интроверты $(25,7 \%)$ как типы личности, руководители работали так, что в конце анализируемого года работа их отделов была высоко оценена. В ходе исследования стало ясно, что у типов руководителя с преобладанием флегматичного типа темперамента $(22,8 \%)$ коллектив, в отличие от руководителей с прочим видом темперамента проявили более эффективную работоспособность 


\begin{tabular}{l|lr|ll|ll} 
& ISRA (India) & $=\mathbf{1 . 3 4 4}$ & SIS (USA) & $=\mathbf{0 . 9 1 2}$ & ICV (Poland) & $=\mathbf{6 . 6 3 0}$ \\
Impact Factor: & ISI (Dubai, UAE) $=\mathbf{0 . 8 2 9}$ & PUHL (Russia) $=\mathbf{0 . 2 0 7}$ & PIF (India) & $=\mathbf{1 . 9 4 0}$ \\
& GIF (Australia) & $=\mathbf{0 . 5 6 4}$ & ESJI (KZ) & $=4.102$ & IIBI (India) & $=\mathbf{4 . 2 6 0}$ \\
& JIF & $=\mathbf{1 . 5 0 0}$ & SJIF (Morocco) & $=\mathbf{2 . 0 3 1}$ & & \\
\hline
\end{tabular}

и показали лучшие результаты. Согласно шкале нейротизма $68,5 \%$ руководителей отделов обладают стабильным, а $31,4 \%$ руководителей нестабильным нейротизмом. Следует отметить, что $77,1 \%$ респондентов ответили на вопросы вполне искренне.

\section{References:}

1. Bajramov A.S., Alizade A.A. (2003) Social'naja psihologija. Baku, 2003.

2. Aliev R. (2008) Psihologija. Nurlan, Baku, 2008.

3. (2007) Psihologija. Pod red. Seidova S.I. i Gamzaeva M.A. Baku, 2007.

4. Kitov A.I. (1984) Psihologija hozjajstvennogo upravlenija. Moskva, Profizdam, 1984.

5. Shpranger Je. (1982) Osnovnye ideal'nye tipy individual'nosti. // Psihologija lichnosti. Teksty. Pod redakciej Ju.B.Gippenrejter, A.A. Puzyreja. Moscow, 1982.

6. Dzhems U. (1982) Dinamika i organizacija lichnosti. // Psihologija lichnosti. Teksty. Pod redakciej Ju.B.Gippenrejter, A.A. Puzyreja. Moscow, 1982.

7. (2005) Sbornik psihologicheskih testov. Chast' I: Posobie / Sost. E.E.Mironova - Mn.:Zhenskij institute JeNVILA, 2005.-155 p.

8. Roshhin S.Ju., Razumova T.O. (2008) [Tekst]: Jekonomika truda. M.: INFRA-Moscow, 2008.$24 \mathrm{p}$.

9. (2005) ES-25: budushhee social'noj politiki [Tekst] // «Chelovek i trud». №3, 2005.-P.46-58

10. Meskon M. (2002) Osnovy menedzhmenta. Per. s angl.Moscow, Delo, 2002.-132 p. 